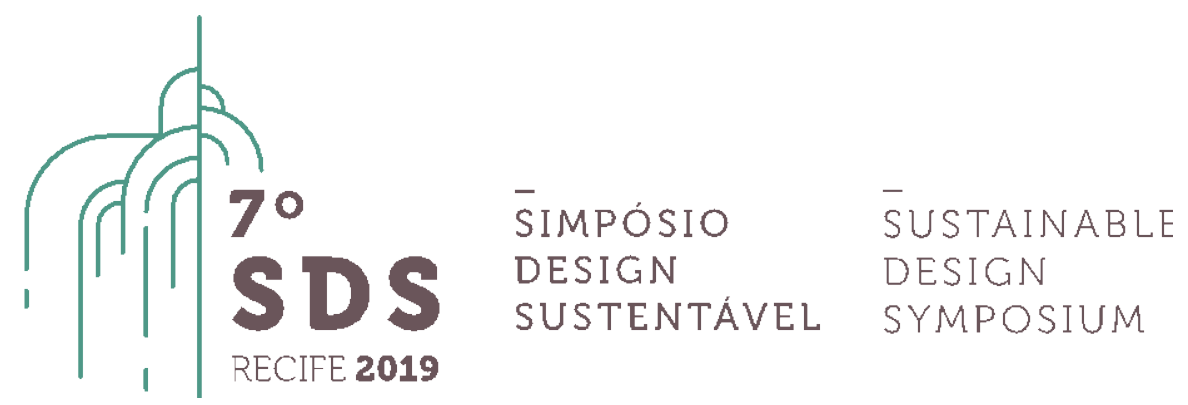

\title{
DESIGN.COM: práticas simpoiéticas no design contemporâneo
}

\author{
Barbara Szaniecki ${ }^{1}$, Talita Tibola ${ }^{2}$, Pedro Biz ${ }^{3}$ e Diego Costa ${ }^{4}$ \\ ${ }^{1}$ ESDI/UERJ, PPDESDI, szanieckibarbara@gmail.com \\ 2 ESDI/UERJ, PPDESDI, talita.tt@gmail.com \\ 3 ESDI/UERJ, PPDESDI, pedrotrg@gmail.com \\ 4 ESDI/UERJ, PPDESDI, dscosta.c@gmail.com
}

\begin{abstract}
Resumo. Neste artigo procuramos aproximar o conceito de sustentabilidade tal como é percebido no campo do design de uma série de noções propostas por antropólogos e filósofos tais como Bruno Latour, Tim Ingold e Donna Haraway. A sustentabilidade pode ser alcançada pela criação de redes, malhas e string figures. A partir dessas formulações teóricas, procuramos apreender práticas que possam orientar o design para a sustentabilidade. São elas as drawing things together de Latour, o making de Ingold e, sobretudo, as práticas simpoiéticas propostas por Haraway. Por fim, apresentamos alguns experimentos articulando design de serviço e design gráfico realizados na Esdi/UERJ. Nosso intuito foi o de testar ferramentas assim como aproximar a noção de sustentabilidade de uma percepção antropológica de estar no mundo com outros.
\end{abstract}

Palavras-chave. Práticas simpoiéticas. Making. Drawing things together. Design para sustentabilidade. Design de serviço. Design de comunicação.

O tema da sustentabilidade não é novo mas o problema não cessa de se agravar. Já em 1968 o Clube de Roma incitou uma reflexão urgente sobre um desenvolvimento atento ao meio ambiente sem perder a ênfase econômica e que passou a ser conhecido como "desenvolvimento sustentável". Nesta mesma década, Félix Guattari (GUATTARI, 1989) sustentava que as ecologias são, no mínimo três - a ambiental, a social e a psicológica, sem predomínio de uma dimensão sobre a outra, incitando uma complexidade para além das abordagens dicotômicas características do pensamento moderno. O tema da sustentabilidade também não é novo no campo do design mas não cessa de se ampliar: também nos anos 70, Victor Papanek (PAPANEK, 1971) nos alertava para a ação do designer nos processos industriais e para as consequências nefastas da produção de massa tanto em termos sociais quanto ambientais. Papanek acusava duramente os designers de incitar um consumo desnecessário que gerava, por sua vez, uma degradação ambiental desenfreada. Mas não deixou de pensar em como o design poderia se transformar. 
Meio século depois do alerta, faz-se necessário pensar e mudar urgentemente nossa atuação no mundo de maneira radical. Trata-se eventualmente de deixar para trás o que é entendido por "ação" e, muitas vezes, até o que sempre foi definido como "humano". Como sair de oposições tais como sujeito versus objeto e cultura versus natureza, que fazem do homem a medida e o centro do Mundo não é tarefa fácil visto que elas estão entranhadas em nossos pensamentos e práticas implementados desde a Antiguidade e foram fortalecidas na era moderna. Existe todo um esforço no campo das ciências e humanas para desconstruí-las e, ao mesmo tempo, evitar a fragmentação característica da pós-modernidade. Urge uma simbiose entre sustentabilidade e humanidade e aqui pretendemos desenvolver de modo a contribuir para esse debate por meio de práticas simpoiéticas em design.

\section{Sustentabilidade: redes, malhas e string figures}

Muitos autores abordam hoje a simbiose entre sustentabilidade e humanidade mas em diferentes termos. Em sintonia com essa questão, Bruno Latour (LATOUR, 2005) sugere, por exemplo, que é preciso reformular as ciências sociais retomando a tarefa de descobrir associações, incluindo os não humanos. Sua teoria ficou conhecida como teoria do ator rede. A Actor Network Theory de Latour ficou conhecida pela sua sigla ANT. Sendo que em inglês ant significa formiga, ela se tornou um emblema das teses proposta por Latour.

Também em sintonia com a necessidade de percepções e propostas alternativas à da modernidade e humanidade hegemônica, mas numa provocação a Latour, Tim Ingold traz em seu texto "quando a formiga se encontra com a aranha: teoria social para artrópodes" um divertido diálogo entre uma formiga e uma aranha, e apresenta a diferença entre a idéia de rede e a de malha. Muito sinteticamente, a rede da teoria do ator-rede da qual a formiga se tornou símbolo supõe uma diferença entre diferentes elementos e as conexões entre eles. Já a idéia de malha, inspirada na teia da aranha, supõe um emaranhado complexo entre os elementos e suas conexões. Por exemplo, segundo a primeira teoria, a de Latour, um galho de árvore, uma teia e uma aranha seriam elementos separados que podem ser conectados. Já segundo a segunda teoria, a das malhas de Ingold, galho, teia e aranha constituem um emaranhado que é o próprio de toda vida (INGOLD, 2015): as linhas da teia constituem a aranha tanto quanto as pernas do seu corpo.

Em seu último livro: Staying with the trouble : making kin in the Chthulucene, a bióloga e filósofa Donna Haraway também dialoga com as questões levantadas por Latour e Ingold (HARAWAY, 2016) introduzindo-nos às suas string figures. Antes de comentá-las, é preciso entender a sua crítica às análises da contemporaneidade em termos de antropoceno e capitoloceno. Haraway não nega que a ação do homem e do capitalismo teve efeitos terríveis no planeta mas propõe as dinâmicas de Chthuluceno - inspirado no nome da aranha Pimoa Cthulhu para superá-las. Nessa era de nome curioso, ela sugere formar parentescos interespécies mais do que organizações humanas para desenvolver o que chama de responsa-habilidade. Uma responsabilidade que é também uma habilidade de responder aos desafios do momento tal como as catástrofes sociais e ambientais.

Aranhas e polvos inspiram o pensamento tentacular da autora, E podem inspirar práticas tentaculares também. Às redes de Latour e às malhas de Ingold, podemos somar as string figures "camas-de-gato" - de Haraway. Elas não se equivalem, muito pelo contrário, entre elas, existem diferentes percepções das relações em questão. No caso de Haraway, string figures são expressões de uma simpoiética, isto é, uma palavra adequada para sistemas complexos, dinâmicos e responsivos. Uma palavra para worlding with, isto é, para "fazer mundo com". Não apenas o mundo não acabou, como seguimos fazendo mundos com os outros mas é preciso desenvolver a responsa-habilidade. Com um design sustentável, por que não? 
Para exemplificar, a autora traz alguns exemplos de experiências, nenhuma delas tem uma relação direta com o design, mas com práticas afins tais como o artesanato e as artes. E todas elas têm relação com práticas simpoiéticas que promoveram "ressurgência", outro termo caro a Haraway. Uma das experiências é o Crochet Coral Reef. O Recife de Coral em Crochê é uma iniciativa de três mulheres que articulou diferentes práticas - da matemática às artes passando pela biologia - e acabou envolvendo mais de 8000 pessoas em 27 países numa resistência científica-artística ao desaparecimento dos corais diante do aquecimento global. Uma outra experiência simpoiética nasceu dos extermínios históricos das ovelhas churro pertencentes à população navajo nos Estados Unidos. Os acontecimentos dramáticos acabaram por gerar ao longo do tempo uma intensa articulação de pastores e tecelãs navajo e indígenas de outras etnias, de estudantes e pesquisadores e de inúmeros ativistas que se estendeu do drama específico de outrora às lutas pela terra e pela água de hoje. A simpoiética se revela, pois, como um "fazer com" que é também um viver e lutar com os outros. O "fazer com" nos leva a pensar em um "design com". E o que isso tem a ver com um design sustentável?

\section{Hipóteses para um design sustentável: drawing things together, making, práticas simpoiéticas.}

Na passagem de uma economia industrial (focada em produtos e em comunicação) para uma economia pós-industrial (mais baseada em serviços e conversação), o design se renovou em termos de pensamentos e práticas. Os autores abordados até aqui não são designers e sequer estão falando explicitamente sobre design, mas todos abrem possibilidades para imaginar um design do século XXI onde a sustentabilidade, em toda sua complexidade, esteja presente.

Com base em Latour, podemos imaginar este design deixando de estar atrelado a noções de construção ou criação de objetos para se aproximar de um drawing things together (LATOUR, 2009), isto é, de um agrupar de coisas heterogêneas e questões através do desenho, com a cautela de um pós-Prometeu. Sai de cena o designer prometeico - um Deusigner - que caracterizou a modernidade. A partir de Ingold, podemos entendê-lo como um making (INGOLD, 2013), isto é, como entrelaçamento complexo de projetos e processos, deixando de se fixar em formas para seguir forças, fluxos. E, de acordo com Haraway, ele se constituiria de práticas simpoiéticas ou fazer com. Essas práticas, contudo, deixariam de querer resolver problemas a todo e qualquer custo. Muito pelo contrário, elas permitiram "ficar com o problema no Chthuluceno", tal como a autora indica. Haraway também sugere que todas as articulações que constituem o "fazer com" também promovem alterações. Ao viver e lutar com os outros, nos afetamos e nos transformamos (HARAWAY, 2016). O design com é um devir com os outros.

Drawing things together, making e design com são todos nomes para um design do século XXI. Um design sustentável é necessariamente um design simpoiético: um design de designers com não designers, de humanos com não humanos. Embora todas as denominações sejam interessantes, por conta da provocação que Ingold faz a Latour, faz-se necessária breve parênteses para salientar que Bruno Latour é o que mais se refere ao design e aos designers. E que a sua proposta não pode ser reduzida à provocação que faz a Tim Ingold. Já em Reagregando o Social: uma introdução a teoria do Ator-Rede, Latour pergunta: "Por que é tão difícil desenhar o social?" (LATOUR, 2006, p. 231)

Mais tarde, em Prometeu Cauteloso (LATOUR, 2008), ele provoca: “Eis a questão que quero colocar aos designers: onde estão as ferramentas de visualização que permitirão representar a natureza contraditória e controversa das questões de interesse?" A provocação é dupla. Por um lado, Latour critica as ciências modernas que ao afirmarem a existência de "questões de fato" negaram que fatos sempre estiveram em disputa e que, portanto, constituem "questões de interesse". Por outro, afirma que questões de interesse requerem ferramentas de 
visualização que não correspondem à visão modernista linear e unificada mas tampouco devem se desfazer em pontos de vista múltiplos e desconexos. O que ele pede é "um meio para agrupar as coisas através do desenho" e pergunta "por que o poderoso vocabulário visual desenvolvido nas gerações passadas de artistas, engenheiros, designers, filósofos, artesãos e ativistas das questões de fato não pode ser elaborado [...]? (LATOUR, 2008, p. 21)

Latour está aqui interessado em ferramentas de desenho, e porque não de design, que dêem conta da natureza contraditória e controversa das questões de interesse. A sustentabilidade é sem dúvida uma delas, das mais importantes! E aqui podemos fechar temporariamente os parênteses sobre a controvérsia entre Latour e Ingold e retornar ao design com os outros inspirado nas práticas simpoiéticas de Haraway. Seria ele suficiente para garantir a sustentabilidade em toda as suas dimensões culturais, sociais, políticas e econômicas, sem sobreposição de um aspecto sobre outro? A pergunta é complexa e aqui não é possível respondêla. Contudo, a apresentação dos exercícios propostos numa disciplina da Esdi/UERJ servem para seguir pensando. Um design simpoiético vai além da mera aplicação de modelos colaborativos formulados em contextos diferentes e requer cautelosos experimentos de campo. Um design simpoético pode levar contribuições ao que se entende tradicionalmente por inovação social e sustentabilidade no campo do design (MANZINI, 2008) mas são os ressurgimentos advindos da responsa-habilidade enquanto capacidade de responder aos desafios do momento que nos interessam em particular.

\section{DESIGN.COM: experimentos de sustentabilidade na Esdi/UERJ}

Em 2017 realizamos alguns experimentos de design voltados para a sustentabilidade no quadro de uma disciplina na Escola Superior de Desenho Industrial da UERJ. A disciplina em questão tem sua origem no tradicional projeto de programação visual mas, com a reforma curricular, ganhou orientação para o design de serviço. Ela é, em suma, um híbrido de design gráfico com design de serviço, ainda em experimentação. Foi realizada na graduação e foi compartilhada com o professor Daniel Portugal. Portugal trabalhou com a metodologia de "personas" e nós trabalhamos com uma metodologia que, por necessidade de dar um nome, chamamos de "design com parceiros". Juntos escolhemos o tema da "alimentação natural". É preciso destacar que o semestre em questão, por conta das dificuldades enfrentadas pela UERJ, foi reduzido a $75 \%$ em termos de aulas. Foi difícil para os professores reduzir as metodologias de projeto previstas inicialmente e ainda mais difícil para os alunos realizá-las no tempo restrito.

Uma vez dividida a turma em dois grupos - o do professor Daniel e o nosso, redividimos o nosso grupo de quinze alunos em três grupos de cinco alunos e cada um deles escolheu um parceiro com quem desenvolver um "serviço". Deixamos claro para os alunos que "serviço" era o termo utilizado no campo do design, profissional ou acadêmico, mas que poderíamos criar ações com objetivos outros. Os parceiros escolhidos foram: o próprio Espaços Verdes, um laboratório de design para agricultura urbana e sustentabilidade que teve início com a criação de uma horta na Esdi, ali mesmo na Lapa, e ao qual Pedro Biz e Diego Costa ativam; o Organicidade, coletivo focado na agricultura urbana e localizado próximo à Esdi, na Fundição Progresso; e a horta da General Glicério, uma horta comunitária no bairro de Laranjeiras.

Apresentamos aos alunos algumas ferramentas visuais - mapas de idéias e dos atores, jornada do usuário, business model canvas e blue prints entre outros. Algumas ferramentas visuais são usadas não apenas no design - design gráfico e design de serviço no nosso caso - como também nas ciências sociais, e Ana Clara Torres Ribeiro foi, com sua "cartografia de ação social", uma das precursoras e principais defensoras dessa ferramenta. Pedimos aos grupos que fossem a campo, procurassem conhecer seus parceiros - Espaços Verdes, Organicidade e Horta da General Glicério - e as relações entre aqueles que participam dessas comunidades. 
Para cada uma delas, os alunos desenharam a rede de conexões, a malha de interações ou suas string figures. Ao colocar esses conceitos lado a lado, não há qualquer intenção de equiparálos. Há somente a intenção de levar em conta que as relações em questão, assim como a possibilidade de apreendê-las através de ferramentas visuais ou simplesmente desenho, varia de campo a campo e de acordo com os envolvidos. Em todo caso, essa etapa foi fundamental antes de prosseguir em direção a uma proposta. Foi fundamental porque não havia nenhum briefing, isto é, nenhuma demanda prévia por parte dos parceiros escolhidos em termos design em geral e ainda menos em termos de design de serviço. No caso do Organicidade, a atividade de serviços existia. No caso do Espaços Verdes e da Horta da General Glicério, mais do que "serviços", "ações" eram cogitadas para dar maior consistência às comunidades.

No caso do Espaços Verdes, a pesquisa de campo levou à percepção de que uma boa parte da comunidade esdiana não conhecia a horta e sua proposta. Não sabia que poderia contribuir com a rega cotidiana e tampouco que poderia usufruir de seus frutos. O primeiro grupo de alunos propôs focar no fortalecimento das relações esdianas num momento de dificuldade por meio dos cuidados e das colheitas da horta. E chegou à proposta de um aplicativo de nome Kypos com funções claras que podem garantir eficiência no manejo da horta, como coordenar a rega e a colheita, mas não necessariamente promovem o engajamento necessário. Já o segundo grupo estendeu o público para além da comunidade esdiana através do fortalecimento das relações com as pessoas que dão oficinas ou que delas participam no Espaços Verdes. O foco foi na geração de um engajamento mais permanente e na troca de conhecimento mais consistente. A proposta chamada Verdesign foi dupla: por um lado um jornal que comunica os eventos de forma mais organizada e, por outro, cartilhas que sistematizam os conhecimentos produzidos na hortalaboratório. A idéia central é que o "esdiano" - aluno, professor ou funcionário pudesse adquirir conhecimentos em sustentabilidade e que, reciprocamente, os "oficineiros" possam adquirir conhecimentos básicos em design para fazerem uma cartilha ou outra peça gráfica simples. Não se trata de mero "ponto de contato" entre, por exemplo, o consumidor e o serviço em um blue print, mas de um "ponto de troca" que faz do oficineiro um designer e do designer um agente de sustentabilidade. É, na realidade, o momento e o movimento em que o ponto se faz linha (INGOLD, 2011). E é preciso que nossas ferramentas visuais os apreendam sem prendê-los.

No caso do Organicidade, a pesquisa de campo indicava que o coletivo nasceu de uma vontade de compartilhar certos valores mas que acaba dedicando parte de seus esforços e energias a serviços para manter essas atividades fundamentais. Essa percepção levou um grupo de alunos a desenvolver uma solução mais comercial enquanto o outro optou por uma proposta mais educativa e lúdica. O primeiro grupo focou num público consumidor interessado em comprar produtos de agricultura urbana, alguns convencionais outros menos, e a proposta foi a de um caminhão que levaria os produtos do Organicidade para feiras e eventos. O serviço de plant truck foi chamado de Org pra Nóbis - um trocadilho com nome de uma PANC, ou seja, uma planta alimentícia não convencional. O segundo grupo apresentou uma proposta mais próxima das intenções iniciais do Organicidade, isto é, de uma sensibilização à questão ambiental através da educação e o público escolhido foi as crianças. Semente é um projeto de oficina para crianças em escolas e de geração de renda para o Organicidade. O design gráfico traz uma linguagem sensível compatível com a proposta educacional mas o tratamento dentro dos padrões do design do serviço, não apenas com as suas ferramentas visuais mas com sua lógica linear, parece ter minimizado sua potência de sensibilização das crianças - atores fundamentais para a sustentabilidade e ressurgimentos possíveis - para uma outra relação com o mundo. O blue print em particular parece recolocar as atividades de serviços e, mais preocupante ainda, as relações humanas, dentro da lógica da produção industrial.

No caso da Horta da General Glicério, a pesquisa indicou a existência de uma iniciativa com 
forte potencial para desdobramentos como também conflitos. Dos dois grupos que foram a campo, apenas um chegou a desenvolver uma proposta. As alunas se deslocaram até o bairro de Laranjeiras para conhecer o local e as várias pessoas envolvidas direta ou indiretamente na horta. A partir desses materiais e por meio de visualizações variadas, analisaram os diferentes tipos de envolvimento das pessoas com a horta - como "as facilitadoras", os "parceiros" e os "vizinhos" - e de relações das pessoas entre si, assim como os problemas e as diferentes perspectivas e expectativas com relação à horta. A água foi identificada como elemento de potencial simultaneamente agregador e desagregador da comunidade por conta do acesso e dos gastos em água. Gerava ao mesmo tempo convivência e conflito. E de tudo isso - da pesquisa de campo com fotos e entrevistas até a prospecção fora de campo com mapas de possibilidades - emergiu no grupo a vontade de criar algo que é muito menos e, ao mesmo tempo, muito mais do que um "serviço".

Ao descrever sua proposta Água Viva, elas afirmam que se trata da "experiência de se tornar um voluntário ativo em uma causa social do bairro - a concepção e manutenção da Horta da General Glicério - oferecendo um bem que todos têm em abundância em casa - a ÁGUA. A proposta do Água Viva é mobilizar a vizinhança em torno da manutenção de um espaço que é de todos por meio de uma ação simbolizada pelo abastecimento dos regadores da Horta da General Glicério carinhosamente denominados de "Glicerinos Regadores". Para além das questões relativas ao cultivo urbano, o projeto Água Viva pretende diversificar os usos do espaço, disseminar o sistema autogestionado que já ocorre na Horta e aproximar indivíduos de expertises variadas para se unir às causas importantes para a comunidade.

Figura 1 e 2 - Projeto Água Viva

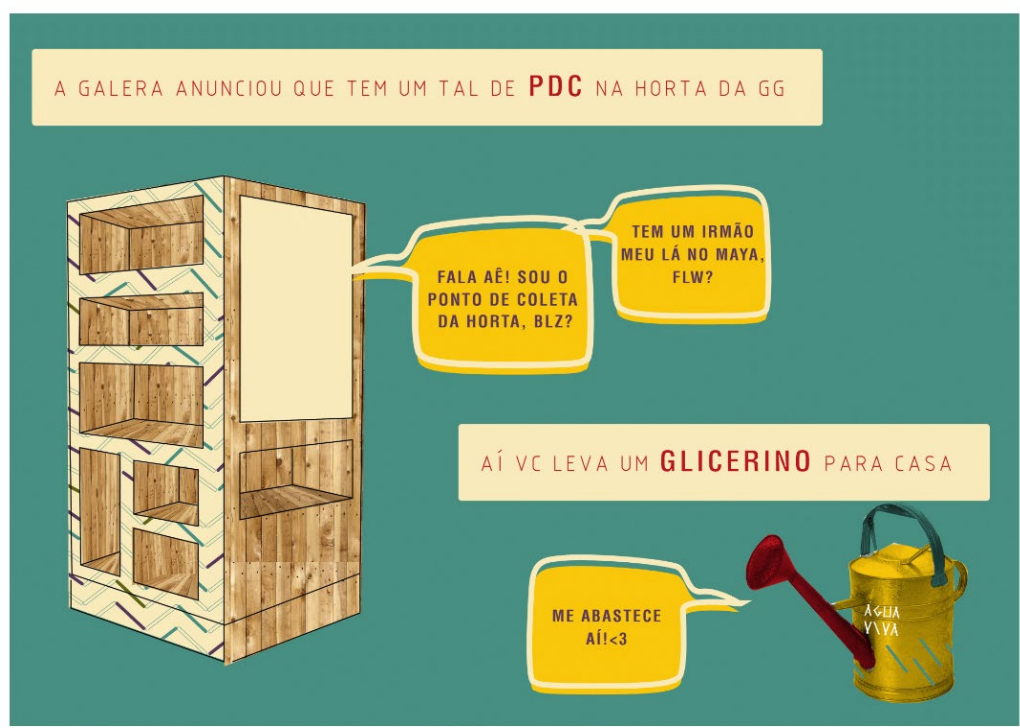




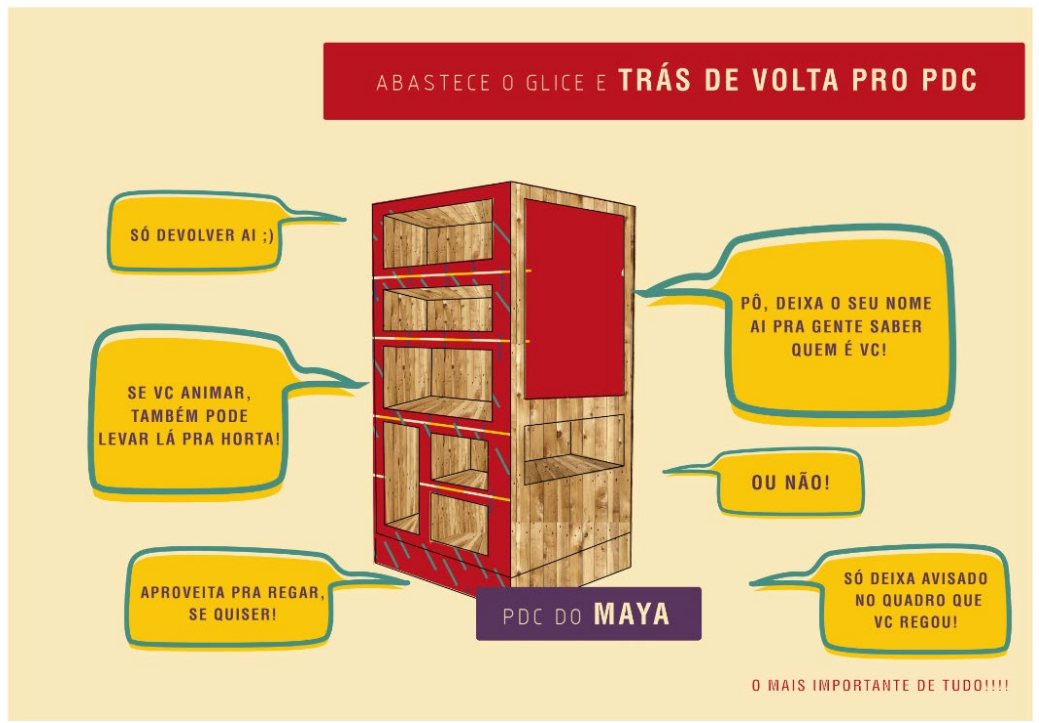

Fonte: Stephanie Lima, Stephanie Gonçalves e Andrea Marroquin (designers do projeto Água Viva)

O projeto não descarta um eventual viés comercial. Existem no bairro feiras livres, comércio amplo e vários restaurantes e bares. Os produtos da horta poderiam, com toda evidência, ser comercializados, seja in natura seja elaborados culinariamente. Mas o grupo de alunos optou por potencializar a comunidade por uma ação que é tão produtiva - gerar frutos quanto política - fortalecer a comunidade. Em suma, do que se trata? Estimular as pessoas a pegarem um regador da horta levá-lo para casa, enchê-lo da água em sua casa e levá-lo de volta à horta. Em caso de disponibilidade de tempo, regar a horta e sinalizar que foi regada. Como elementos centrais dessa trama temos a diversidade dos humanos, desde os mais animados com a horta até os vizinhos preocupados com o uso da água dos prédios próximos, como também dos não humanos desde o regador, uma ferramenta um tanto anacrônica mas tão simpática que chega a ganhar um nome ("Seu Glicerino") até a água. Esta corre nem sempre por canos e, portanto, depende de muitas mãos para chegar à horta e de outras visões de mundo para chegar a um bem estar comum.

\subsection{Espaços Verdes}

Como apresentado anteriormente, os experimentos se deram com parceiros. A parceria com a sociedade é fundamental para nós e a entendemos como um dos pilares da sustentabilidade da universidade. Na disciplina, foram parceiros a Horta da General Glicério, o Organicidade e o Espaços Verdes. Este último, interno à Esdi, além de cuidar da horta como um exercício de experimentação e vivência em agricultura urbana, desenvolve outras pesquisas, tais como o design plantado, no qual propõe-se a cultivar mobiliários nas árvores em crescimento, tendo a participação da própria árvore no desenho, ao conduzir seus ramos e brotos por caminhos não esperados por seu parceiro designer. Outro projeto é o Arranjo Local Penha, uma rede de atores sociais de diversas áreas que promovem ações voltadas para a agricultura urbana no complexo da Penha, Rio de Janeiro, impulsionando o debate sobre alimentação saudável e agroecologia. Os esforços são direcionados a construir condições para a formação de uma comunidade simbiótica entre as pessoas, instituições, plantas e território. Poderia-se mencionar ainda a configuração da horta e o arranjo de plantas cultivado como outro projeto sempre em devir e, sendo assim, a horta é encarada como um laboratório vivo.

Os projetos são desenvolvidos durante o processo e entre as coisas que os envolvem, seres vivos e não vivos, humanos e não humanos, abordagem denominada design micelial. Assim, "o 
design é mais um fio em uma trama em fluxo, operando no tempo em que os nós se enlaçam, [...] corpo e ambiente participando de uma mesma coisa chamada fluxo da vida. O projeto não é linear e o resultado não é acabado, mas construído em uma ação coletiva em atenção e transformação com o ambiente" (BIZ et al. 2018, p. 8).

\section{Considerações finais}

Iniciamos este artigo abrindo a possibilidade de apreender a sustentabilidade por meio de três dimensões: a ambiental, a social e a psicológica. Encontramos em formulações teóricas tais como redes, malhas e string figures de Latour, Ingold e Haraway respectivamente, algumas pistas para dar conta dessa complexidade. E, aproximando-nos do campo do design mais especificamente, nos deparamos com algumas hipóteses formuladas pelos mesmos autores para um design sustentável como drawing things together, como making e como práticas simpoiéticas. Ainda assim, era preciso testar, na materialidade do campo e no encontro com atores locais, a efetividade dessas propostas. Uma disciplina realizada na Esdi/UERJ nos deu essa possibilidade.

A organização das muitas mãos para levar água até a horta: existe metáfora mais adequada para a nossa existência no mundo? Essa fragilidade existencial é, paradoxalmente, a força de nossas articulações. As propostas dos alunos apresentaram potências e problemas interessantes. Dos seis projetos apresentados, dois tinham como questão comum a água e, mais precisamente, a irrigação de uma horta - a do Espaços Verdes na Esdi e a da rua General Glicério, além de certa dificuldade das propostas em "se encaixar" nos modelos do design de serviço e nas suas ferramentas de visualização. A passagem da era industrial para a era pós-industrial, do design de produtos para o design de serviços focado em inovação social e modelos colaborativos não resolve a questão da sustentabilidade. A experiência dos Espaços Verdes na Esdi sugere que para alcançar a sustentabilidade no design faz-se necessária uma mudança de postura ética que amplie a visão de um design centrado no humano para um design em relação ao ambiente e todas as formas de vida (BIZ et al, 2018). A eficiência deve se aliar à sensibilidade com a alteridade.

Tais modelos e ferramentas têm mérito pois eles certamente nos ajudam a "organizar" o "serviço". Mas constatamos que, se por um lado eles são capazes de representar as articulações entre os sujeitos, por outro eles dificilmente conseguem expressar as alterações nas subjetividades e os diferentes tipos de "ação no mundo ou ação com o mundo - worlding with que essas iniciativas envolvem. O design pode mais em suas variações de práticas drawing things together, making e simpoiésis e representações do mundo em redes, malhas e string figures com suas diferenças. Pensar em formas mais sensíveis de captar e fazer mundo na complexidade do tecido das relações entre humanos, não humanos, coisas, é um desafio para quem pretende fazer do design uma ferramenta de transformação rumo à sustentabilidade. Donna Haraway tem razão. O nome da nossa era é Chthuluceno, é uma ecologia afetiva que é um fazer com os outros. É a era do design com os outros que é também um devir com os outros, ou seja, um processo coletivo incessante com infinitas e infinitesimais alterações. E as três estudantes responsáveis pela ação Água Viva proposta aos participantes da Horta da General Glicério têm mais razão ainda: "Um mais um dá dez".

O presente trabalho foi realizado com apoio da Coordenação de Aperfeiçoamento de Pessoal de Nível Superior - Brasil (CAPES)

\section{BIBLIOGRAFIA}

BIZ, Pedro; COSTA, Diego; THEMOTEO, Pedro; SOARES, Flávia; SZANIECKI, Bárbara e ANASTASSAKIS, Zoy. Design micelial. Uma proposta para agricultura urbana a partir dos projetos do Laboratório Espaços Verdes da ESDI-UERJ. Lugar Comum: Estudos de mídia, cultura e 
democracia. Universidade Nômade, n. 53, mai.-dez. 2018.

GUATTARI, Félix. Les trois écologies. Paris: Galilée, 1989.

HARAWAY, Donna. Staying with the trouble: making kin in the Chthulucene. Durham and London: Duke University Press, 2016.

INGOLD, Tim. Une brève histoire des lignes. Éditions Zones Sensibles, 2011.

INGOLD, Tim. Making - anthropology, archeology, art and architecture. London and New York: Routledge, 2013.

INGOLD, Tim. Estar vivo: ensaios sobre movimento, conhecimento e descrição. Petrópolis: Vozes, 2015.

LATOUR, Bruno. Changer de société. Refaire de la sociologie. Paris: La Découverte, 2006.

LATOUR, Bruno. Um Prometeu cauteloso? Alguns passos rumo a uma filosofia do design (com especial atenção a Peter Slotedijk). Palestra para o encontro Networks of Design, da Design History Society. Falmouth, Cornualha, 3 de setembro de 2008. http://filosofiadodesign.com/wpcontent/uploads/2014/10/Prometeu-cauteloso.pdf

MANZINI, Ézio. Design para a inovação social e sustentabilidade: comunidades criativas, organizações colaborativas e novas redes projetuais. Rio de Janeiro: E-papers, 2008.

PAPANEK, Victor. Design for the real world: human ecology and social change. New York: Pantheon Books, 1971. 